\title{
Erratum to: The influence of antibiotic prophylaxis on bacterial resistance in urinary tract infections in children with spina bifida
}

Sebastiaan Hermanus Johannes Zegers ${ }^{1 *}$, Jeanne Dieleman ${ }^{1}$, Tjomme van der Bruggen $^{2}$, Jan Kimpen ${ }^{3}$ and Catharine de Jong-de Vos van Steenwijk ${ }^{3}$

\section{Erratum}

In this version of this article that was originally published [1] there was an error in the author list with an alternative name for the first author, 'Sebastiaan Hermanus Johannes Zegers', being incorrectly listed as the last author, 'Bas Zegers'. The original article has been updated to delete the duplicate author name, 'Bas Zegers', and to correctly list 'Sebastiaan Hermanus Johannes Zegers' as the corresponding author.

\footnotetext{
Author details

'Máxima Medical Center, Post box 77775500, MB, Veldhoven, The Netherlands. ${ }^{2}$ University Medical Center, Utrecht, The Netherlands. ${ }^{3}$ Wilhelmina Children's Hospital, University Medical Center, Utrecht, The Netherlands.
}

Received: 15 February 2017 Accepted: 15 February 2017

Published online: 27 February 2017

\section{Reference}

1. Zegers SHJ, Dieleman J, van der Bruggen T, Kimpen J, De Jong-de-Vos van Steenwijk C. The influence of antibiotic prophylaxis on bacterial resistance in urinary tract infections in children with spina bifida. BMC Infect Dis. 2017;17:63.

\footnotetext{
* Correspondence: b.zegers@mmc.nl

'Máxima Medical Center, Post box 77775500, MB, Veldhoven, The Netherlands
} 